\title{
Effect of limestone particle size on egg production and eggshell quality of hens during late production
}

\author{
F.H. de Witt ${ }^{\#}$, N.P. Kuleile, H.J. van der Merwe and M.D. Fair \\ Department of Animal, Wildlife and Grassland Sciences, University of the Free State, P.O. Box 339, \\ Bloemfontein 9300, South Africa
}

\begin{abstract}
A study was conducted to determine the influence of different particle size limestone in layer diets on egg production and eggshell quality during the later stages of egg production ( $>54$ weeks of age). Calcitic limestone $(360 \mathrm{~g} \mathrm{Ca} / \mathrm{kg})$, consisting of small $(<1.0 \mathrm{~mm})$, medium $(1.0-2.0 \mathrm{~mm})$ and large $(2.0-3.8 \mathrm{~mm})$ particles were obtained from a specific South African source that is extensively used in poultry diets Isoenergetic (14.32 MJ AME/kg DM) and isonitrogenous (172.01 g CP/ $/ \mathrm{kg} \mathrm{DM})$ diets with a dietary Ca content of $39.95 \mathrm{~g} \mathrm{Ca} / \mathrm{kg}$ DM were used. Sixty nine, individual caged Lohmann-Silver pullets, 17 weeks of age, were randomly allocated to the three treatments $(n=23)$ for the determination of various egg production and eggshell quality characteristics. Egg production and eggshell quality data recorded on individual basis at $54,58,64$ and 70 weeks of age were pooled to calculate and statistical analysed parameter means for the late production period. Different limestone particle sizes had no effect on any of the tested egg production and eggshell quality parameters. These results suggested that larger particles limestone are not necessarily essential to provide sufficient $\mathrm{Ca}^{2+}$ to laying hens for egg production and eggshell quality at end-of-lay, provided that the dietary $\mathrm{Ca}$ content satisfies the requirements of the laying hen.
\end{abstract}

Keywords: Lohmann-Silver, feed efficiency, egg weight, eggshell thickness, calcification

${ }^{\#}$ Corresponding author. E-mail: dewittfh.sci@ufs.ac.za

\section{Introduction}

Butcher \& Miles (2005) indicated that eggshell breakage is directly related to eggshell quality and the capacity of the shell to withstand external forces. It is estimated that between 14.3 and $21.3 \%$ of the total number of eggs laid worldwide, are either cracked or broken before they reached the final consumer (Chrystal, 2000). Due to the financial implications of eggshell breakages, as well as associated health risks related to cracked shells, eggshell quality still remains one of the primary concerns to the poultry industry. Eggshell formation normally occurs during night time, when no feed consumption occurs, emphasizing the birds dependence on intestinal and skeletal calcium (Ca) reserves for shell calcification. Scott et al. (1971), Brister et al. (1981) and Farmer et al. (1986) suggested that the prolonged retention time of larger particles limestone in the acidic environment of the gizzard would provide more available ionic calcium $\left(\mathrm{Ca}^{2+}\right)$ during night-time, which could be utilized for eggshell calcification. Consequently, the maintenance of adequate $\mathrm{Ca}$ reserves in the gastrointestinal tract (GIT) would reduce the dependency on skeletal Ca for eggshell formation, thereby limiting the mobilization of medullary Ca reserves (Farmer et al., 1986). Other authors (Roland, 1986; Keshavarz \& McCormick, 1991) also reported an improvement in eggshell quality and egg weight by replacing a part of ground limestone with larger particles. However, due to confounded effects such as differences in Ca sources, particle sizes, age and genotype of birds as well as dietary $\mathrm{Ca}$ inclusion levels, it is enigmatic to make meaningful comparisons between documented studies. Recommendations regarding the ideal limestone particle size for layers are under continued investigation and ranged generally between 1.40 and $5.60 \mathrm{~mm}$, depending on the production status and age of the birds. These divergent recommendations clearly indicate the need for more defined margins in terms of the ideal limestone particle size at different production stages.

The aim of the study was to determine the effect of a specific South African limestone source, differing in particle sizes, on egg production and eggshell qualities during late production. 


\section{Materials and Methods}

All procedures conducted during this study were approved by the Control Committee for Animal Experimentation of the University of the Free State (Animal Experiment No. 13/06). Limestone (360.0 g $\mathrm{Ca} / \mathrm{kg} \mathrm{DM})$ obtained from a commercial supplier, were graded according to particle size as small $(<1.0 \mathrm{~mm})$, medium $(1.0-2.0 \mathrm{~mm})$ and large $(2.0-3.8 \mathrm{~mm})$, representing the three treatments. The experimental diet, containing $172.01 \mathrm{~g}$ crude protein $/ \mathrm{kg} \mathrm{DM}, 14.32 \mathrm{MJ}$ apparent metabolisable energy $/ \mathrm{kg} \mathrm{DM}, 51.05 \mathrm{~g}$ fat $/ \mathrm{kg}$ $\mathrm{DM}, 39.95 \mathrm{~g} \mathrm{Ca} / \mathrm{kg} \mathrm{DM}$ and $6.44 \mathrm{~g}$ available phosphorus $/ \mathrm{kg} \mathrm{DM}$ was supplied to the animals for the duration of the experimental period. Sixty-nine (69) individually caged $\left(1600 \mathrm{~cm}^{2} / \mathrm{bird}\right)$ Lohmann-Silver pullets, 17 weeks of age $(1655 \pm 18 \mathrm{~g})$, were randomly allocated to the three treatments $(\mathrm{n}=23)$ and housed in a natural ventilated building. Egg production and eggshell quality data recorded on individual basis at 54, 58, 62 and 70 weeks of age were pooled to calculate and statistical analyzed parameter means for the late production period. Daily egg numbers were recorded during the mentioned weeks and hen-day egg production (Ahmad \& Balander, 2003) was calculated and expressed as mean egg production (\%). Individual egg weights were recorded for all eggs produced and used to calculate mean egg weight for the experimental period. After recording egg weight, individually marked eggs were broken in two halves at the equator (Strong, 1989; Kul $\&$ Seker, 2004) and washed under slowly flowing water to remove adhering albumen. Washed shells were allowed to dry for an hour at room temperature, before eggshell thickness measurements were conducted. A micrometer $(0.01 \mathrm{~mm})$ was used to make three shell thickness measurements per measurement point on the blunt end, equator and sharp end of individual eggs, resulting in a total of nine measurement readings per egg (Ehtesham \& Chowdhury, 2002; Ahmad \& Balander, 2003). After recording eggshell thickness, individual shells were stored for the determination of dry shell weight and shell ash content (Clunies et al., 1992). Eggshell quality variables such as egg surface area (Carter, 1975), shell weight per unit surface area (SWUSA) (Wells, 1967), percentage eggshell (Orban \& Roland, 1990) and eggshell Ca (g) were calculated.

Individual feed intake was determined on a weekly basis and used to calculate the average daily feed intake of hens, expressed as $\mathrm{g} / \mathrm{hen} / \mathrm{day}(\mathrm{g} / \mathrm{h} / \mathrm{d})$, during late production. Feed conversion ratios (FCR) were determined by dividing the mean feed intake by the mean egg weight and expressed as gram feed per gram egg produced $(\mathrm{g} / \mathrm{g})$. The PROC ANOVA procedure of the SAS programme (SAS, 1999) was used to test for significant $(\mathrm{P}<0.05)$ differences between treatments.

\section{Results and Discussion}

The effects of different particle sizes limestone on egg production, egg weight, feed intake and feed conversion ratio during late production are presented in Table 1. These results are in accordance with the findings of Cheng \& Coon (1990) and Scheideler (1998) who concluded that limestone particle size had no effect on egg production performance parameters. Contrary to the present findings, Guinotte \& Nys (1991) reported that larger particles $\mathrm{Ca}$ supplements resulted $(\mathrm{P}<0.01)$ in a higher feed intake compared to finer particles. However, the increased feed intake as recorded by Guinotte \& Nys (1991) was not accompanied $(\mathrm{P}>0.05)$ by an increase in egg production, feed efficiency or increased body weight, and they speculated that the increase in feed intake due to larger particles $\mathrm{Ca}$ had resulted in heavier eggs $(\mathrm{P}>0.05)$.

Table 1 The effect of different particle sizes limestone on production parameters of layers during late production (Mean \pm s.e.)

\begin{tabular}{cccccc}
\hline \multirow{2}{*}{ Parameter } & \multicolumn{3}{c}{ Particle size $(\mathrm{mm})$} & \multicolumn{2}{c}{ Significance } \\
\cline { 2 - 6 } & $<1.0$ & $1.0-2.0$ & $2.0-3.8$ & $\mathrm{P}^{1}$ & \\
\hline & & & & \\
Egg production (\%) & $82.65 \pm 0.02$ & $82.31 \pm 0.02$ & $79.25 \pm 0.02$ & 0.40 & 10.9 \\
Egg weight (g) & $61.32 \pm 0.82$ & $59.93 \pm 0.95$ & $59.59 \pm 0.78$ & 0.32 & 6.5 \\
FCR ${ }^{3}(\mathrm{~g} / \mathrm{g})$ & $1.67 \pm 0.03$ & $1.65 \pm 0.03$ & $1.70 \pm 0.03$ & 0.50 & 8.7 \\
\hline
\end{tabular}

\footnotetext{
${ }^{1}(\mathrm{P}>0.05)=$ non significant.

${ }^{2}$ Coefficient of variation.

${ }^{3}$ Feed conversion ratio.
} 
Since limestone particle size had no effect $(\mathrm{P}>0.05)$ on any of the tested parameters, differences in results between the former mentioned and the present study could probably be ascribed to differences in genetic strain, environmental and housing conditions as well as the interaction between limestone source, particle size and dietary ingredients.

The effects of different particle sizes limestone on eggshell quality characteristics are presented Table 2. Different particle sizes limestone had no effect $(\mathrm{P}>0.05)$ on any of the tested parameters during late production. These results are contrary to that of Scott et al. (1971), Brister et al. (1981) and Koreleski \& Swiatkiewicz (2004) who reported that larger particles Ca supplements had generally an ameliorating effect on eggshell quality. These authors suggested that the prolonged exposure time of large particles $\mathrm{Ca}$ supplements to $\mathrm{HCl}$ acid in the gizzard, due to their slower transit time, resulted in an increased dissociation of $\mathrm{CaCO}_{3}$ into bio-available $\mathrm{Ca}^{2+}$ that could be utilized by the fowl for eggshell calcification as well as replenishment of medullary bone reserves. They also suggested that this beneficial effect of large particles Ca supplements are more pronounced in older hens ( $>48$ weeks of age), due to their increased Ca demands for shell calcification and skeletal maintenance and their decreased capability of dietary Ca absorption. Since the anticipated beneficial effects of larger particles limestone on eggshell quality characteristics were not observed during the present study, it could be postulated that either the dietary limestone content fulfil in the requirements of the hens and/or that the solubility of the smallest $(<1.0 \mathrm{~mm})$ particles of this specific limestone source was sufficient for optimal eggshell quality during late production.

Table 2 The effect of different particle sizes limestone on eggshell quality characteristics of layers during late production (Mean \pm s.e.)

\begin{tabular}{cccccc}
\hline \multirow{2}{*}{ Parameter } & \multicolumn{3}{c}{ Particle size $(\mathrm{mm})$} & \multicolumn{2}{c}{ Significance } \\
\cline { 2 - 6 } & $<1.0$ & $1.0-2.0$ & $2.0-3.8$ & $\mathrm{P}^{1}$ & $\mathrm{CV}^{2}(\%)$ \\
\hline Shell weight (g) & $5.83 \pm 0.09$ & $5.78 \pm 0.12$ & $5.81 \pm 0.08$ & 0.94 & 7.7 \\
Eggshell (\%) & $9.51 \pm 0.11$ & $9.65 \pm 0.14$ & $9.76 \pm 0.11$ & 0.35 & 5.7 \\
Shell ash (g) & $0.25 \pm 0.01$ & $0.26 \pm 0.01$ & $0.25 \pm 0.01$ & 0.83 & 8.3 \\
Shell Ca (g) & $2.17 \pm 0.04$ & $2.16 \pm 0.04$ & $2.17 \pm 0.04$ & 0.94 & 7.7 \\
ESA $^{3}\left(\mathrm{~cm}^{2}\right)$ & $72.58 \pm 0.69$ & $71.41 \pm 0.80$ & $71.12 \pm 0.65$ & 0.32 & 3.3 \\
SWUSA $^{4}\left(\mathrm{mg} / \mathrm{cm}^{2}\right)$ & $80.28 \pm 0.93$ & $80.88 \pm 1.17$ & $81.67 \pm 0.84$ & 0.61 & 5.6 \\
Shell thickness (mm) & & & & & \\
Blunt end & $0.36 \pm 0.00$ & $0.36 \pm 0.00$ & $0.36 \pm 0.00$ & 0.95 & 6.8 \\
Equator & $0.38 \pm 0.00$ & $0.39 \pm 0.00$ & $0.39 \pm 0.00$ & 0.35 & 6.5 \\
Sharp end & $0.37 \pm 0.00$ & $0.36 \pm 0.00$ & $0.37 \pm 0.00$ & 0.70 & 8.0 \\
\hline
\end{tabular}

\footnotetext{
$(\mathrm{P}>0.05)=$ non significant.

2 Coefficient of variation.

3 Egg surface area.

${ }^{4}$ Shell weight per unit surface area.
}

In support to the present study, Cheng \& Coon (1990) and Guinotte \& Nys (1991) concluded that larger particles limestone had no beneficial effect on egg production or eggshell quality characteristics, provided that dietary $\mathrm{Ca}$ levels $(\geq 36.0 \mathrm{~g} \mathrm{Ca} / \mathrm{kg})$ are optimum. The hypotheses of these authors was that the beneficial effect of larger particles limestone on eggshell quality diminishes as dietary Ca levels increase from marginal to optimal, suggesting that dietary Ca levels are fundamentally more important to ensure proper eggshell quality than the physical size of the Ca source. Since the dietary Ca content of the present study was $39.95 \mathrm{~g} \mathrm{Ca} / \mathrm{kg} \mathrm{DM}$, it could be concluded that the hypothesis of the former authors was supported by the present findings. From the present study, it seems that limestone with a minimum particle size of at least $1.0 \mathrm{~mm}$ would supply sufficient $\mathrm{Ca}^{2+}$ to laying hens during later stages of production, without any detrimental effect on egg production and eggshell quality. 


\section{Conclusions}

Results from the present study indicated that large particle size limestone had no beneficial effect on egg production and eggshell quality characteristics of laying hens at later stages ( $>54$ weeks of age) of production. These results suggested limestone particles $(\geq 1.0 \mathrm{~mm})$ from this specific source would supply sufficient $\mathrm{Ca}^{2+}$ to maintain proper egg production and eggshell quality, provided that a dietary $\mathrm{Ca}$ level of at least $39.95 \mathrm{~g} \mathrm{Ca} / \mathrm{kg} \mathrm{DM}$ and/or a daily Ca-intake of $3.96 \mathrm{~g} / \mathrm{hen} /$ day is maintained.

\section{References}

Ahmad, H.A. \& Balander, R.J., 2003. Alternative feeding regimen of calcium source and phosphorus level for better eggshell quality in commercial layers. J. Appl. Poult. Res. 12, 509-514.

Brister Jr, R.D., Linton, S.S. \& Creger, C.R., 1981. Effects of dietary calcium sources and particle size on laying performance. Poult. Sci. 60, 2648-2654.

Butcher, G.D. \& Miles, R.D., 2005. Concepts of eggshell quality. http://www.afn.org/poultry/flkman4.htm

Carter, T.C., 1975. The hen's egg: A rapid method for routine estimation of flock mean shell thickness. Br. Poult. Sci. 16, 131-143.

Cheng, T.K. \& Coon, C.N., 1990. Effects of layer performance and shell quality of switching limestone with different solubilities. Poult. Sci. 69, 2199-2203.

Chrystal, P., 2000. South African Limestone: The cheap ingredient. http://www.spesfeed.co.za/Autumn\%202000.htm

Clunies, M., Parks, D. \& Leeson, S., 1992. Calcium and phosphorus metabolism and eggshell thickness in laying hens producing thick or thin shells. Poult. Sci. 71, 490-498.

Ehtesham, A. \& Chowdhury, S.D., 2002. Responses of laying hens to diets formulated by using different feeding standards. Pak. J. Nutr. 1, 127-131.

Farmer, M., Roland Sr, D.A. \& Clark, A.J., 1986. Influence of dietary calcium on bone calcium utilization. Poult. Sci. 65, 337-344.

Guinotte, F. \& Nys, Y., 1991. Effects of particle size and origin of calcium sources on eggshell quality and bone mineralization in egg laying hens. Poult. Sci. 70, 583-592.

Keshavarz, K. \& McCormick, C.C., 1991. Effects of sodium aluminosilicate, oyster shell and their combinations on acid-base balance and eggshell quality. Poult. Sci. 70, 313-325.

Koreleski, J. \& Swiatkiewicz, S., 2004. Calcium from limestone meal and grit in laying hen's diet - effect on performance, eggshell and bone quality. J. Anim. Feed Sci. 13, 635-645.

Kul, S. \& Seker, I., 2004. Phenotypic correlations between some external and internal egg quality traits in the Japanese quail (Coturnix coturnix japonica). Int. J. Poult. Sci. 6, 400-405.

Orban, J.I. \& Roland Sr, D.A., 1990. Correlation of eggshell quality with tibia status and other production parameters in commercial Leghorns at oviposition and 10-hour postoviposition. Poult. Sci. 69, 2068-2073.

Roland Sr, D.A., 1986. Eggshell quality IV: Oyster shell versus limestone and the importance of particle size or solubility of calcium source. World Poult. Sci. J. 42, 166-171.

SAS, 1999. SAS ${ }^{\circledR}$ User's Guide. Version 6.12. SAS Institute Inc. Cary, N.C., USA.

Scheideler, S.E., 1998. Eggshell calcium effects on egg quality and Ca-digestibility in first or third cycle laying hens. J. Appl. Poult. Res. 7, 69-74.

Scott, M.L., Hull, H.J. \& Mullenhoff, P.A., 1971. The calcium requirements of laying hens and effect of dietary oyster shell upon eggshell quality. Poult. Sci. 50, 1055-1063.

Strong Jr, C.F., 1989. Relationship between several measures of shell quality and egg breakage in a commercial processing plant. Poult. Sci. 68, 1730-1733.

Wells, R.G., 1967. Eggshell strength. The relationship between egg breakage in the field and certain laboratory assessments of shell strength. Br. Poult. Sci. 8, 131-139. 